\title{
Crédito rural agrícola e impactos regionais sobre a dinâmica da produção agrícola brasileira no período de 2000 a 2010
}

\author{
José Raimundo B. Trindade ${ }^{1}$ \\ Adejard Gaia Cruz ${ }^{2}$
}

\begin{abstract}
Resumo: Este artigo examina o crédito rural, tendo como ponto de apoio metodológico os indicadores de concentração, especialização, localização e desigualdade tal como se especificará na seção metodológica deste trabalho. 0 estudo analisa exclusivamente o crédito rural agrícola, objetivando problematizar o impacto deste sobre as condições de expansão da agricultura brasileira no período de 2000 a 2010, considerando os indicadores mencionados para focalizar a distribuição do crédito rural em nível nacional, centrado nas macrorregiões do Instituto Brasileiro de Geografia e Estatística (IBGE), sob o recorte municipal. Os indicadores mostram que aproximadamente $84 \%$ dos municípios com elevada disponibilidade de crédito agrícola estão concentrados no Sul e Sudeste em 2010, sendo irrisória a participação da Região Norte, cuja evolução entre os indicadores de 2000 para 2010 foram insignificantes (passou de 0,5 \% para 0,7 \%). Dessa forma, a maior concentração dos municípios de precária ou inexistente disponibilidade creditícia apresenta-se nas regiões Norte e Nordeste, o que reforça a importância de se pensar novas políticas públicas regionalizadas de oferta de crédito agrícola.
\end{abstract}

Palavras-chave: Crédito rural agrícola. Desenvolvimento regional. Indicadores de concentração.

Classificação JEL: Q14, Q19, R58.

\section{Rural credit and regional impacts on the dynamics of agricultural production of Brazil in recent period}

\begin{abstract}
This article examines rural credit, employing measures of concentration, specialization, location and inequality, which are specificed in the methodological section of this paper. The study is only analyzing agricultural credit, aiming to problematize the impact of the same on the conditions of expansion of Brazilian
\end{abstract}

1 Professor e pesquisador Associado II do Programa de Pós-graduação em Economia da UFPA; Doutor em Desenvolvimento Econômico pelo Programa de Pós-graduação em Desenvolvimento Econômico da UFPR, e-mail: jrtrindade@ufpa.br.

2 Doutor em Economia pelo Programa de Pós-graduação em Economia da UFPA e Economista da Secretaria de Planejamento do Governo do Estado do Pará, e-mail: adejardgaia@gmail.com. 
agriculture in the period from 2000 to 2010, but considering the indicators mentioned and focussing on the distribution of agricultural credit at the national level. The macro regions employed correspond to the definitions of the IBGE, for municipalities. The indicators show that approximately $84 \%$ of municipalities with high availability of agricultural credit are concentrated in the South and Southeast of Brazil in the year 2010. In contrast, the participation of the North is miniscule, having grown from $0.5 \%$ to $0.7 \%$ during the period 2000 to 2010 . Another result was that the highest concentration of the cities with extremely limited or nonexistent credit was clearly in the North and Northeast regions. This reinforces the importance of new public policies aimed at improving regionalized supply of agricultural credit.

Keywords: Agricultural credit. Regional development. Indicators of concentration.

\section{Introdução}

O estudo que se segue analisa o Crédito Rural Agrícola, tendo como ponto de apoio metodológico a construção de indicadores de concentração, especialização, localização e desigualdade tal como se especificará na seção metodológica deste trabalho. 0 estudo analisa exclusivamente o crédito rural agrícola, considerando os indicadores mencionados para focalizar a distribuição do crédito rural em nível nacional, centrado nas macrorregiões do IBGE$^{3}$, sob o recorte municipal, objetivando problematizar o impacto do crédito agrícola sobre as condições de expansão da agricultura brasileira no período de 2000 a 2010.

Vale observar que a análise proposta se coloca dentro do marco das abordagens dos impactos das finanças no espaço econômico. Diversas compreensões teóricas buscam entender como o espaço econômico é formado, sendo que as diferentes dinâmicas regionais resultam de uma diversidade de aspectos, um dos quais e, talvez, de grande importância é a disponibilidade de crédito e sua diferente distribuição no território, isso em conformidade com a dinâmica espacial da acumulação capitalista. A novidade expressa neste artigo refere-se primeiramente ao tratamento em nível inter-regional das condições de disponibilidade de crédito, especificamente utilizando-se de ferramentas estatísticas que aproximam o "look in" do crédito em termos municipais e, em segundo nível, a análise estrutural do perfil do crédito rural brasileiro.

0 artigo está dividido em cinco seções, além deste breve introito. 0 texto faz, inicialmente, uma breve exposição de aspectos teóricos e histórico-descritivos do crédito rural agrícola e sua relação com o desenvolvimento regional. Isso se faz necessário considerando a perspectiva da inserção do crédito sob um marco

3 As cinco macrorregiões: Norte (sete estados); Nordeste (nove estados); Centro-Oeste (três estados e o distrito federal); Sudeste (quatro estados); Sul (três estados). 
interpretativo diferenciado, que o tenha como uma variável relevante para a dinâmica de expansão capitalista no espaço regional. Na parte metodológica expõem-se como o uso dos indicadores nos permite construir uma tipologia para os 5.507 municípios brasileiros. Na seção principal constrói-se a base de análise regional, utilizando-se dos indicadores em apreço para focalizar a distribuição do crédito rural em nível nacional, sob o recorte municipal, buscando analisar os indicadores e considerando o perfil tipológico e sua aplicação às municipalidades; e finalmente, apresentam-se as considerações finais e algumas proposições em termos de políticas a serem aplicadas ao crédito rural agrícola.

\section{Crédito rural agrícola e desenvolvimento regional: uma primeira aproximação analítica e territorial}

O debate sobre o tema desenvolvimento e sua relação com os aspectos agrários se alterou bastante nas últimas décadas, deixando de ser somente a elucidação dos fatores referentes a uma maior ou menor taxa de crescimento e participação do agrário no Produto Interno Bruto (PIB) total, para passar a incorporar outros aspectos mais qualitativos e, de diversos modos, mais integrados a uma "teoria geral do capitalismo", considerando, inclusive, a dificuldade de orientar um conjunto tão grande e distinto de vetores sociais, econômicos, ambientais e institucionais.

A lógica básica do desenvolvimento nos países centrais do capitalismo foi descrita por Furtado (2000), Meier (2001), entre outros, nos termos de estímulo tecnológico possibilitado pela escassez de mão de obra e sua transição entre o urbano e o rural. A questão central apontada seria a de que os sistemas desses países no pós-guerra caminharam para a adoção de políticas de pleno emprego e na medida em que se empregava todo o estoque de mão de obra, havia uma pressão pelo aumento das taxas de salários reais que, por sua vez, alimentavam a engrenagem da inovação técnica que, via desemprego tecnológico, tenderia a baixar novamente as taxas salariais e aumentar a taxa de lucro. Esse círculo virtuoso somente era completado se estivesse garantida a demanda solvente via taxas elevadas de crescimento econômico, o que de fato se deu até meados da década de 60 - o que se convencionou chamar de fordismo ou keynesianismo, o golden age do capitalismo.

Autores mais recentes da teoria do desenvolvimento, como Rodrik (2000) e Chang (2003), observam que um dos aspectos centrais no desenvolvimento se refere à disponibilidade e capacidade governativa das instituições, especialmente às que se destinam ao controle do mercado (regulação), ao planejamento do desenvolvimento e à disponibilização de crédito. Os diversos contextos históricos demonstram que quanto mais maduras as referidas instituições maiores as facilidades de as sociedades superarem barreiras aos novos estágios de desenvolvimento. 
Condicionante central para se pensar o desenvolvimento regional e a relação com os aspectos agrários refere-se a análise das finanças, especialmente, aos fatores de oferta e demanda de crédito rural. Em termos, ainda muito gerais, Chick (2006) pondera que a variável finanças atua de forma diferenciada em "economias centrais" vis-à-vis "economias periféricas". Considerando diferentes interpretações (teoria da causação cumulativa, teoria da dependência e a teoria keynesiana), a autora em foco observa que a tendência predominante é a de aprofundamento da distância entre centro e periferia pelo sistema de financiamento, ou nos termos postos por ela: "o investimento tenderá a concentrar-se nessas regiões [centrais]: êxito gera êxito e taxas de crescimento e/ou níveis de atividades econômicas provavelmente irão divergir" (CHICK, 2006, p.79).

Conning e Udry (2007) chamam atenção para o fato que a organização da atividade econômica rural em geral, e da produção agrícola particular, é fortemente condicionada pelo tempo de produção e pelas adversidades naturais, além das oscilações de mercado. Nesses ambientes, a capacidade das empresas agrícolas e das famílias produtoras de fazerem investimentos em longo prazo, assumir riscos calculados e criar fluxos de consumo estáveis, será muito influenciada pela presença de instrumentos de crédito estáveis; aponta os autores que se o conjunto disponível de serviços financeiros é muito limitado, os produtores rapidamente tendem a renunciar a investimentos e a geração de atividades mais rentáveis, sofrendo as consequências da volatilidade do mercado.

Essa percepção é assemelhada àquela defendida por Cavalcante et al. (2006, p. 302) em que o crédito "faz a ligação necessária para o gap financeiro produtivo". Enfim, a discussão sobre desenvolvimento tem se ampliado e possibilitado enfoques e leituras de diferentes níveis do território. Análises macro, teorias de desenvolvimento (e técnicas de análise) regional, desenvolvimento local constituem-se como possibilidades de diagnósticos e construção de proposições visando à transformação do território e a inserção de aspectos de financiamento e políticas de crédito.

A análise do crédito agrícola como elemento de impacto na estrutura produtiva local, condicionando o setor agrário das economias locais e o modusoperandi deste, constitui aspecto importante e pouco estudado, sendo que vincula dois aspectos centrais: as finanças na condição expansiva da acumulação setorial e centralizada de capital e o território como espaço de produção ou realização do valor econômico.

Vale notar que os estudos internacionais acerca do crédito agrícola demonstram que, infelizmente, os produtores nos setores rurais da maioria dos países em desenvolvimento permanecem deslocados das oportunidades de acesso ao crédito para investimento, elevando os riscos e diminuindo as oportunidades de diversificação produtiva aos pequenos e médios produtores (CONNING, J., \& UDRY, C., 2007; BARRY, P., \& ROBISON, L., 2001; CLOKE, P., MARSDEN, T., \& MOONEY, P., 2006). 
No Brasil, o sistema de crédito aplicado à agricultura e à pecuária é, em larga escala, centrado nas instituições financeiras públicas, porém, com alguma participação das instituições bancárias privadas e de outras modalidades de financiamento. O Banco Central (Bacen) e o Conselho Monetário Nacional (CMN) fornecem ao governo federal controle sobre o sistema de crédito em geral, inclusive o crédito rural, sendo que o Sistema Nacional de Crédito Rural (SNCR), criado em 1965, mediante Lei $\mathrm{n}^{\circ} 4.829$, estabeleceu desde então uma forte regulação setorial, mas que sofreu fortes alterações nas décadas recentes, especialmente nos anos de $1990^{4}$.

Convém observar que o SNCR tinha em termos de seus objetivos o fortalecimento dos pequenos e médios agricultores e o uso do crédito subsidiado como política pública de combate às possíveis distorções macroeconômicas e de solução de problemas de curto prazo (IPEA, 2010, p. 360; BUAINAIN \& GARCIA, 2013). Vale destacar que com a criação do Programa de Fortalecimento da Agricultura Familiar (Pronaf), em 1996, observa-se uma pequena inflexão na disponibilização de crédito para os pequenos produtores, porém como se mostrará no artigo, a lógica do SNCR será ao longo das décadas de manter a proeminência da disponibilidade do crédito para a grande produção (agronegócio).

Vale reforçar que a maior parte da oferta de empréstimos rurais ainda é suprida pelo Banco do Brasil (BB) e por outros bancos públicos (Banco do Nordeste do Brasil S.A. - BNB, Banco da Amazônia, Banco Nacional Desenvolvimento Econômico e Social -_BNDES). De modo geral, como demonstram diversos estudos (IPEA, 2010; CROCCO \& JAYME JR., 2006; SANTANA, 2005; GASQUES, VERDE \& OLIVEIRA, 2004; BUAINAIN \& GARCIA, 2013), o crédito rural no Brasil tem uma dupla face: é em grande medida ofertado por instituições públicas, centrado, inclusive, em programas constitucionalizados ou historicamente enraizados; segundo, é fortemente concentrado no Sul e Sudeste do país como se mostrará. Bouainain et al (2014) observam que constituem o "tripé da política agrícola atual" o crédito rural, o seguro rural e o Pronaf, o que, segundo os autores acima citados, esvazia políticas públicas de outros tipos e necessárias, como a "a defesa sanitária vegetal e animal, ao comércio exterior, a infraestrutura e logística, a regulação de várias áreas relevantes e a Ciência, Tecnologia e Informação (CT\&I) para a agricultura", por outro lado, torna mais relevante a análise e acompanhamento do SNCR.

Como aponta estudo do Instituto de Pesquisa Econômica Aplicada -Ipea (2010, p. 361) três características gerais da política de crédito rural influenciam a maior ou menor disponibilidade do crédito agrícola no Brasil. A primeira refere-se às menores taxas de juros do segmento em relação às praticadas em outros

4 Para uma análise bastante circunstancial do crédito rural no Brasil conferir Kumar (2004) e Ipea (2010). Para este sobrevoo ao crédito rural seguiremos de perto os dois artigos citados. 
empréstimos, o que produziu certo subsídio aos tomadores de crédito, especialmente no período de elevadas taxas de inflação (1973 a 1993); uma segunda característica vinculou-se à política de crédito barata, baseada em fundos do Tesouro Nacional; e, por último, a segmentação produzida pela criação do Pronaf, em 1996, com objetivo social e distributivo, sendo que nesse programa as taxas nominais de juros dos empréstimos feitos aos grupos de produtores da agricultura familiar são fixadas em níveis inferiores das praticadas em relação aos agricultores comerciais.

Por mais que as características do crédito agrícola pareçam apontar para o estímulo ao pequeno produtor, não é isso que se observa. González-Vega (1987) aponta que o crédito tem efeito regressivo na distribuição da renda dos agricultores brasileiros, segundo aquele autor, quase " $90 \%$ das fazendas não relataram nenhum empréstimo de fontes formais ou informais no Censo de 1970, e essa proporção teria caído para 80\%, em 1980", sendo que a década de 1990 teria apresentado quadro ainda mais difícil para a pequena produção, somente parcialmente revertido com o Pronaf (GONZÁLEZ-VEGA, 1987; GASQUES, VERDE \& OLIVEIRA, 2004; IPEA, 2010; BUAINAIN \& GARCIA, 2013). A característica de seletividade do crédito acaba por definir uma dupla identidade assimétrica do mesmo: distribui-se desigualmente entre tomadores individuais e regiões (Ipea, 2010). Aspecto a ser conferido, com base nos indicadores analisados, refere-se como a estrutura de crédito se comportou na última década, reforçando ou não a definida assimetria da disponibilidade de crédito em nível regional.

Observa-se, ainda, que algumas inovações creditícias no Brasil devem-se às reformas constitucionais promovidas pela Constituição Federal de 1988, especialmente a criação dos Fundos Constitucionais de Financiamento - Fundo Constitucional da Região Norte (FNO), Fundo Constitucional da Região Nordeste (FNE) e Fundo Constitucional da Região Centro-Oeste (FNCO) -, gerados pelo percentual de $3 \%$ da arrecadação do Imposto sobre Produtos Industrializados (IPI) e do Imposto de Renda (IR) para aplicação de crédito subsidiado nas regiões Norte $(0,6 \%)$, Nordeste $(1,8 \%)$ e Centro-Oeste $(0,6 \%)$; estes com a concepção inicial de priorizar os pequenos produtores rurais e industriais das referidas regiões, cuja característica histórica (especialmente do Norte e Nordeste) é a de menor acesso ao crédito agrícola. As instituições que trabalham com esses recursos são o Banco da Amazônia no Norte; o Banco do Nordeste do Brasil (BNB) no Nordeste; e o Banco do Brasil (BB) no CentroOeste. Neste sentido, o indicador de especialização creditícia poderá nos informar quanto ao grau de interatividade e influência desses fundos públicos na atual estrutura de crédito rural dessas regiões, especialmente na Região Norte e Amazônia Legal.

Azzoni (2005, p. 551-552) observa que diversos setores da economia seriam "footloose" (sem raízes), o que facilitaria, no caso da indústria, sua possível desconcentração regional; observa, porém, que no caso das "atividades agrícolas e extrativas, por seu turno, são obviamente vinculadas a fatores naturais e oferecem pouco interesse em termos de programas de desconcentração econômica". Parece- 
nos que o autor em tela desconsidera a centralidade do fator creditício no estímulo específico de tais atividades, de tal modo que a agricultura, a exemplo de outros setores reprodutivos capitalistas, requer uma base creditícia que possibilite sua expansão. Desse modo, parece visível que a expansão de linhas de crédito no Nordeste, a partir da década de 1990 e, especialmente, no Centro Oeste, foi fator estimulante ao efeito "footloose" em dois setores de exportação agrícola: na fruticultura, no caso do semiárido nordestino e na produção de cereais no cerrado mato-grossense (GASQUE et al., 2004; TRINDADE \& OLIVEIRA, 2011).

0 crédito agrícola realiza-se dividido em três segmentos de diferentes importâncias. Um deles é que o crédito para investimento assume um perfil fundamental se tratarmos da necessidade de inovação tecnológica e expansão da produção agrícola, como nota Fürstenau (1987, p. 144) a "importância da disponibilidade de recursos com a finalidade de investimento provém do fato de que é este tipo de aplicação que introduz ou amplia o uso de técnicas mais produtivas alterando, em geral definitivamente, os ganhos de produtividade da terra e do trabalho". Outro é que a manutenção do sistema de produção requer uma capacidade de custeio que, conforme as lavouras envelhecem, torna-se mais necessário, de tal forma que são os créditos de curto prazo, no caso do crédito de custeio, que absorvem a maior parcela do total dos recursos destinados à atividade rural. Por fim, conforme aumenta a escala de produção o financiamento comercial assume relevo considerável.

\section{Fonte de dados e metodologia}

\subsection{As fontes primárias de dados utilizadas e as variáveis processadas}

A base de dados de crédito rural municipalizada utilizada neste trabalho está disponível no sítio do Banco Central do Brasil (Bacen), sendo que anualmente a instituição financeira consolida as estatísticas de crédito rural no "Anuário Estatístico do Crédito Rural", institucionalizado pela Lei $\mathrm{n}^{\circ}$. 4.829, de 05 de novembro de 1965, e regulamentado pelo Manual do Crédito Rural (MCR) anexo à Resolução do CMN (Conselho Monetário Nacional) n ${ }^{\circ}$ 580, de 29 de novembro de 1979, e atualizações posteriores. A referida base é coletada anualmente pelas agências estaduais do Bacen, sendo especificadas em duas modalidades padrões: crédito rural agrícola e crédito rural destinado à pecuária. Essas duas modalidades estão divididas em três tipos: custeio, investimento e comercialização. Vale ainda esclarecer que os dados são consolidados como totalidade do SNCR, abrangendo, portanto, três segmentos: i) produtores e cooperativas; ii) Pronaf ; e, iii) cooperativas. A análise realizada tem como base os dados disponibilizados para o primeiro segmento de produtores e cooperativas. 
Além das estatísticas descritivas, a referida base de dados subsidiou o processamento dos índices de análise regional, a saber, índices de especialização, localização e de concentração, bem como o processamento do índice desigualdade, tendo como período de referência os anos de 2000 e de 2010 e como recorte espacial analítico os municípios do Brasil.

Para permitir compatibilidades de informações e análises comparativas dos índices em uma mesma base territorial entre os dois períodos de referência, a pesquisa recorreu ao uso da técnica de Áreas Mínimas Comparáveis (AMCs) ${ }^{5}$, que estabeleceu 5.507 municípios brasileiros tanto para o ano de 2000 como para o ano de 2010.

Cabe ressaltar que uma parcela desses municípios não demandou crédito rural para os dois anos em análise, não sendo possível, consequentemente, fazer a aferição dos indicadores e, por essa razão, tais municipalidades foram tratadas na condição de "não disponibilidade de crédito" (municípios do tipo D).

0 universo das informações que foram tratadas e processadas envolveu um número significativo de variáveis que foram organizadas por modalidade de crédito, por dimensão geográfica (Brasil) e classificadas em seis níveis (classes), conforme descrito na Tabela 1 abaixo.

Tabela 1: Número e valor de contrato (em valor corrente e \%) por tipo de crédito agrícola (2000/2010)

\begin{tabular}{c|c|c|c|c|c|c|c|c}
\hline \multirow{2}{*}{ Tipo de Crédito CRÉDITO AGRÍCOLA } \\
\cline { 2 - 10 } & $\mathrm{N}^{\circ}$ Contratos & $\%$ & $\begin{array}{c}\text { Valor } \\
\text { (R } \$ 1,00)\end{array}$ & $\%$ & $\begin{array}{c}\mathrm{N}^{\circ} \\
\text { Contratos }\end{array}$ & $\%$ & $\begin{array}{c}\text { Valor } \\
(\mathrm{R} \$ 1,00)\end{array}$ & $\%$ \\
\hline Custeio & 1.057 .089 & 97,3 & 7.434 .536 .560 & 68,2 & 950.321 & 73,6 & 34.433 .443 .669 & 60,5 \\
\hline Investimento & 119.876 & 11,0 & 1.268 .232 .421 & 11,6 & 289.220 & 22,4 & 10.178 .616 .282 & 17,9 \\
\hline Comercialização & 18.674 & 1,7 & 2.201 .989 .486 & 20,2 & 51.134 & 4,0 & 12.319 .657 .688 & 21,6 \\
\hline Total & 1.086 .707 & 100,0 & 10.904 .758 .467 & 100,0 & 1.290 .675 & 100,0 & 56.931 .717 .639 & 100,0 \\
\hline
\end{tabular}

Fonte: Bacen, 2000-2010. Elaboração dos autores.

5 O uso de AMCs consiste na agregação dos municípios desmembrados, mantendo, para efeitos de compatibilização das informações, os mesmos nomes e códigos dos municípios de origem, estabelecidos pelo IBGE. 


\subsection{A descrição dos indicadores utilizados}

Para realizar o processamento dos índices propostos, os dados foram organizados em uma matriz de informações, tendo como inputs numéricos as seguintes variáveis: valor do crédito, indicada genericamente como $\boldsymbol{X}$ para medir o fenômeno espacial de cada uma das três categorias de crédito (custeio, comercialização e investimento); designadas por $\boldsymbol{k}$ (classes), para as quais se dispõe dos valores desagregados para a modalidade agrícola; e por $\boldsymbol{I}$ as unidades territoriais (neste caso os municípios), para as 27 unidades da federação.

Os indicadores utilizados nas análises de espacialização e na construção dos padrões tipológicos do crédito rural agrícola foram os seguintes:

\subsubsection{Coeficiente de Especialização (CEi)}

Este obtido comparando-se a distribuição setorial da variável na unidade territorial $\boldsymbol{I}$ com a distribuição setorial da variável no espaço de referência, neste caso o Brasil (HADDAD, 1989; COSTA, DENTINHO E NIJKANP, 2011).

$$
\text { (1) } C E_{i}=\frac{1}{2} \sum_{k=1}^{K}\left|\frac{x_{i k}}{x_{i}}-\frac{x_{k}}{x}\right|
$$

O CEi tem seu intervalo de variação entre zero (indicando maior diversidade) e um (indicando maior especialização), sendo dado pela equação (1).

\subsection{2 Índice de Entropia Normalizado (ENi)}

O índice de entropia para uma dada unidade territorial é definido pela equação (2) (COSTA, DENTINHO E NIJKANP, 2011):

$$
\text { (2) } E_{i}=-\sum_{k=1}^{K}\left(\frac{x_{i k}}{x_{i}}\right) \log \left(\frac{x_{i k}}{x_{i}}\right), E_{i} \in[0, \log K]
$$

Por convenção $\left(\frac{x_{\mathrm{ik}}}{x_{\mathrm{i}}}\right) \log \left(\frac{x_{\mathrm{ik}}}{x_{\overline{\mathrm{i}}}}\right)=0_{\mathrm{g}}$ uando o setor de atividade (classe de crédito) não se encontra representado nessa unidade espacial. 
Para normalizar o valor do indicador de entropia utiliza-se a equação (3):

$$
\text { (3) } E_{i}=\frac{\log K-E_{i}}{\log K}
$$

Quando normalizado, o índice de entropia varia entre zero e um e, tal como o índice de Rogers, associa a situação de mínima especialização ao limite inferior e a de máxima especialização ao limite superior do intervalo de variação.

\subsubsection{Coeficiente de Reestruturação da Região (CRi)}

O CRi permite avaliar, em dois momentos distintos, a evolução das características de especialização de uma região (município) diante do espaço de referência (Brasil) e pode ser definido pela equação (4) (HADDAD, 1989; COSTA, DENTINHO E NIJKANP, 2011):

$$
\text { (4) } C R_{i}=\frac{1}{4} \sum_{k=1}^{K}\left|\left(\frac{x_{i k}}{x_{i}}-\frac{x_{k}}{x}\right)_{t+1}-\left(\frac{x_{i k}}{x_{i}}-\frac{x_{k}}{x}\right)_{t}\right|
$$

Se o coeficiente de reestruturação for igual a 0 (zero), não terá havido modificações na composição setorial da região. Por outro lado, se o coeficiente for igual a 1 (um) indicará que houve uma modificação profunda na composição setorial da região, do momento t para o momento $t+1$.

\subsubsection{Coeficiente de Variação (CVi)}

Para medir o grau de desigualdade regional no crédito rural o trabalho também fez uso do Coeficiente de Variação (CVi), que conforme Hoffman (1998), é uma das medidas de desigualdade mais antiga e comumente utilizada na literatura, em razão da sua facilidade de cálculo e interpretação dos resultados, tendo como critério a sensibilidade decrescente às transferências. 0 CVi é dado pela equação (5):

(5) $C V i=\frac{\sqrt{\frac{1}{T-1} \Sigma\left(y_{\mathrm{i}}-\mu\right)^{2}}}{\mu}$

Em que yi é o valor per capita da variável $\boldsymbol{X}$ na unidade territorial i; $\mu$, o valor per capita da variável $\boldsymbol{X}$ no espaço de referência; T é o número de unidades territoriais analisadas. 0 coeficiente de variação é, portanto, resultado da razão do 
desvio padrão dividido pela média. Quando o valor do índice CVi for igual a 0 (zero) indicará que não existem desigualdades entre as diferentes classes do fenômeno sob análise em uma determinada unidade territorial e, quanto maior seu valor, maior o grau de desigualdade entre as classes.

\subsection{5 Índice de Concentração Normalizado (ICn)}

O padrão de concentração do crédito rural foi inferido por meio do Índice de Concentração Normalizado ICn, cujos parâmetros para o cálculo tem por base uma combinação linear de outros três indicadores: Quociente Locacional (QL), o Indicador de Participação Relativa (IPR) e o Hirschman-Herfindahl modificado (IHHm). O ICn pode ser formalmente descrito conforme a equação (6) e é detalhado pormenorizadamente, em Crocco et al. (2003) e Crocco, 2006:

\section{(6) $I C n=\theta_{1} Q L+\theta_{2} I P R+\theta_{3} H H m$}

\subsection{A construção dos padrões tipológicos}

Territorialmente, definimos a disponibilidade de crédito como a relação econômica entre a oferta institucional, pública ou privada, de capital de empréstimo que resulta da demanda estabelecida em certo espaço econômico decorrente de três tipos possíveis de recursos requeridos: i) custeio, que se refere à demanda de capital de empréstimo para manutenção do complexo agrário produtivo, seja a pequena produção familiar, seja a grande produção na forma de monocultura ou cultura consorciada; ii) comercialização, destinada ao processo de escoamento e colocação da produção em médios e grandes centros consumidores ou para exportação da produção, em média pouco requisitada pela pequena produção familiar ou empresarial; iii) investimento, destinado a expansão da lavoura ou estrutura de maquinário necessário ao processo reprodutivo do capital agrícola, em grande maioria requisitado pela média e grande produção, com pequena requisição por parte da produção familiar.

Com base na importância de cada uma das modalidades expostas, o crédito de custeio foi privilegiado como base principal para assentamento da tipologia agrícola. Tendo como referência o valor do Índice de Concentração Normalizado (ICn) construiu-se uma tipologia para os municípios brasileiros, centrada na acessibilidade e disponibilidade do crédito rural.

As municipalidades foram divididas em nove (09) padrões básicos, como mostra o Quadro I abaixo. Essa tipologia partiu dos seguintes fatores de definição, tomando como base os ICn's para o crédito rural agricola: a) considerou-se os valores superiores à média do ICn nacional, na seguinte ordem de importância: i) 
ICn Valor Custeio; ii) ICn Valor Comercialização; iii) ICn Valor Investimento; b) estabeleceu-se uma padronização decrescente: Elevada Disponibilidade de Crédito (A1,A2); Média Disponibilidade de Crédito (A3, B1); Baixa Disponibilidade de Crédito (B2, B3); Precária Disponibilidade de Crédito (C1, C2); Sem Disponibilidade de Crédto (D). A partir dos critérios expostos no formato lógico definidos no quadro abaixo se construiu uma função padrão que está exposta na última linha do referido quadro.

Quadro 1: Padrões básicos do crédito rural brasileiro, obtidos com base no ICn Valor.

\begin{tabular}{|c|c|c|}
\hline Tipologia & Padrão & Formato Lógico Agrícola \\
\hline A1 & $\begin{array}{c}\text { Elevada } \\
\text { Disponibilidade }\end{array}$ & $\begin{array}{l}\text { ICn Valor Custeio > Média } \\
\text { ICn Valor Comercialização> Média } \\
\text { ICn Valor Investimento> Média }\end{array}$ \\
\hline $\mathrm{A} 2$ & $\begin{array}{c}\text { Elevada } \\
\text { Disponibilidade }\end{array}$ & $\begin{array}{l}\text { ICn Valor Custeio > Média } \\
\text { ICn Valor Comercialização > Média } \\
\text { ICn Valor Investimento< Média }\end{array}$ \\
\hline A3 & $\begin{array}{c}\text { Média } \\
\text { Disponibilidade }\end{array}$ & $\begin{array}{c}\text { ICn Valor Custeio > Média } \\
\text { ICn Valor Comercialização< Média } \\
\text { ICn Valor Investimento> Média }\end{array}$ \\
\hline B1 & $\begin{array}{c}\text { Média } \\
\text { Disponibilidade }\end{array}$ & $\begin{array}{c}\text { ICn Valor Custeio > Média } \\
\text { ICn Valor Comercialização< Média } \\
\text { ICn Valor Investimento< Média }\end{array}$ \\
\hline $\mathrm{B} 2$ & $\begin{array}{c}\text { Baixa } \\
\text { Disponibilidade }\end{array}$ & $\begin{array}{l}\text { ICn Valor Custeio < Média } \\
\text { ICn Valor Comercialização> Média } \\
\text { ICn Valor Investimento> Média }\end{array}$ \\
\hline B3 & $\begin{array}{c}\text { Baixa } \\
\text { Disponibilidade }\end{array}$ & $\begin{array}{l}\text { ICn Valor Custeio < Média } \\
\text { ICn Valor Comercialização> Média } \\
\text { ICn Valor Investimento < Média }\end{array}$ \\
\hline C1 & $\begin{array}{c}\text { Precária } \\
\text { Disponibilidade }\end{array}$ & $\begin{array}{c}\text { ICn Valor Custeio < Média } \\
\text { ICn Valor Comercialização< Média } \\
\text { ICn Valor Investimento> Média }\end{array}$ \\
\hline $\mathrm{C} 2$ & $\begin{array}{c}\text { Precária } \\
\text { Disponibilidade }\end{array}$ & $\begin{array}{c}\text { ICn Valor Custeio < Média } \\
\text { ICn Valor Comercialização< Média } \\
\text { ICn Valor Investimento< Média }\end{array}$ \\
\hline $\mathrm{D}$ & $\begin{array}{c}\text { Sem } \\
\text { Disponibilidade }\end{array}$ & Não há disponibilidade de crédito \\
\hline \multicolumn{2}{|c|}{ Função Padrão Agrícola } & $\begin{array}{c}=\mathrm{SE}(\mathrm{E}(\mathrm{D} 1=0 ; \mathrm{F} 1=0 ; \mathrm{H} 1=0) ; " \mathrm{D} \text {;SE(E(D1>=0,09;F1>=0,223;H1>=0,41);"A1"; } \\
\text { SE(E(D1>=0,09;F1>=0,223;H1<0,41);"A2";SE(E(D1<0,09;F1>=0,223;H1> } \\
=0,41) ; " \mathrm{~A} 3 " ; \mathrm{SE}(\mathrm{E}(\mathrm{D} 1<0,09 ; \mathrm{F} 1>=0,223 ; \mathrm{H} 1<0,41) ; " \mathrm{~B} 1 " \text {;SE(E(D1>=0,09;F1< } \\
\text { 0,223;H1>=0,41);"B2";SE(E(D1>=0,09;F1<0,223;H1<0,41);"B3";SE(E(D1< } \\
\text { 0,09;F1<0,223;H1>=0,41);"C1";"C2"))))))) }\end{array}$ \\
\hline
\end{tabular}

Fonte: Elaboração dos autores. 
A análise tipológica apresentada no Quadro I (a partir dos Índices de Concentração Normalizados) será cruzada com as faixas identificadas no Quadro II seguinte (obtidas com base no Coeficiente de Especialização (CEi) e Índice de Entropia Normalizado (ENi)), permitindo estabelecer a interação entre os diferentes indicadores especificados, sendo que para sua construção lança-se mão das estatísticas descritivas dos referidos indicadores relacionados na Tabela 2 abaixo.

Tabela 2- Estatística descritiva dos indicadores de especialização e desigualdade $(2000 / 2010)$

\begin{tabular}{|c|c|c|c|c|c|c|c|}
\hline \multirow{2}{*}{$\begin{array}{l}\text { Estatísticas } \\
\text { Descritivas }\end{array}$} & \multicolumn{3}{|c|}{ Indicadores (2000) } & \multicolumn{3}{|c|}{ Indicadores (2010) } & \multirow[b]{2}{*}{ CRi } \\
\hline & $\mathrm{CEi}$ & Eni & $\mathrm{CVi}$ & CEi & Eni & $\mathrm{CVi}$ & \\
\hline Média & 0,5 & 0,63 & 0,87 & 0,5 & 0,5 & 0,95 & 0,18 \\
\hline Máximo & 0,97 & 1 & 2,22 & 0,96 & 1 & 2,32 & 0,65 \\
\hline Mínimo & 0,04 & 0,08 & 0,86 & 0,07 & 0,07 & 0 & 0 \\
\hline Mediana & 0,43 & 0,62 & 0,94 & 0,47 & 0,47 & 0,95 & 0,15 \\
\hline $\begin{array}{l}\text { Desvio } \\
\text { Padrão }\end{array}$ & 0,22 & 0,22 & 0,57 & 0,2 & 0,19 & 0,4 & 0,11 \\
\hline Curtose & $-1,06$ & $-0,96$ & $-1,01$ & $-1,19$ & 0,11 & 0,02 & 1,33 \\
\hline $\begin{array}{l}\text { Assimetria } \\
\text { de Pearce }\end{array}$ & 0,9 & 0,26 & $-0,21$ & 0,38 & 0,39 & $-0,18$ & 0,82 \\
\hline
\end{tabular}

Fonte: Bacen, 2000-2010. Elaboração dos autores.

Quadro 2: Faixas de especialização diversificação do crédito rural (2000/2010)

\begin{tabular}{|c|c|c|c|}
\hline \multicolumn{2}{|c|}{ CEi (2000) } & \multicolumn{2}{c|}{ ENi (2000) } \\
\hline Faixa & Característica Lógica & Faixa & $\begin{array}{c}\text { Característica } \\
\text { Lógica }\end{array}$ \\
\hline $\begin{array}{c}\text { (A1) Restrita } \\
\text { especialização }\end{array}$ & $\begin{array}{c}<=0,276 \text { (Média - Desvio } \\
\text { Padrão) }\end{array}$ & $\begin{array}{c}\text { (A) Grande } \\
\text { Diversificação }\end{array}$ & $\begin{array}{c}<=0,413 \\
\text { (Média - DP) }\end{array}$ \\
\hline (A2) Baixa Especialização & $>0,276$ e <=0,5001 & $\begin{array}{c}\text { (B) Média } \\
\text { Diversificação }\end{array}$ & $>0,413$ e <=0,634 \\
\hline (B) Especialização Média & $\begin{array}{c}>0,5001 \text { e }<=0,7242 \\
\text { (Média + Desvio Padrão) }\end{array}$ & $\begin{array}{c}\text { (C) Baixa } \\
\text { Diversificação }\end{array}$ & $\begin{array}{c}>0,634 \text { e }<=0,854 \\
\text { (Média + DP) }\end{array}$ \\
\hline $\begin{array}{c}\text { (C) Especialização Ampla } \\
\text { (D) Restrita } \\
\text { Diversificação }\end{array}$ & $\begin{array}{c}>0,7242 \text { e }<=0,9483 \\
\text { (Média + 2(DP) }\end{array}$ & \\
\hline $\begin{array}{c}\text { (D) Especialização } \\
\text { Irrestrita }\end{array}$ & $>0,99483$ & & \\
\hline
\end{tabular}


(continuação)

\begin{tabular}{|c|c|c|c|}
\hline \multicolumn{2}{|c|}{ CEi (2010) } & \multicolumn{2}{c|}{ ENi (2010) } \\
\hline Faixa & Característica Lógica & Faixa & $\begin{array}{c}\text { Característica } \\
\text { Lógica }\end{array}$ \\
\hline $\begin{array}{c}\text { (A1) Restrita } \\
\text { especialização }\end{array}$ & $\begin{array}{c}<=0,300 \text { (Média - Desvio } \\
\text { Padrão) }\end{array}$ & $\begin{array}{c}\text { (A) Grande } \\
\text { Diversificação }\end{array}$ & $\begin{array}{c}<=0,310 \text { (Média - } \\
\text { DP) }\end{array}$ \\
\hline (A2) Baixa Especialização & $>=0,300$ e <=0,495 & $\begin{array}{c}\text { (B) Média } \\
\text { Diversificação }\end{array}$ & $>0,310$ e <=0,496 \\
\hline (B) Especialização Média & $\begin{array}{c}>0,495 \text { e }<=0,690 \text { (Média } \\
+ \text { Desvio Padrão) }\end{array}$ & $\begin{array}{c}\text { (C) Baixa } \\
\text { Diversificação }\end{array}$ & $\begin{array}{c}>0,496 \text { e <=0,682 } \\
\text { (Média + DP) }\end{array}$ \\
\hline $\begin{array}{c}\text { (C) Especialização Ampla } \\
\text { (D) Especialização } \\
\text { Irrestrita }\end{array}$ & $\begin{array}{c}\text { (D) Restrita } \\
\text { Diversificação }\end{array}$ & $>0,868$ \\
\hline $\begin{array}{c}\text { (D) }<=0,884 \text { (Média } \\
+2(D P)\end{array}$ & & \\
\hline
\end{tabular}

Fonte: Elaboração dos autores.

\section{Crédito rural agrícola e padrões tipológicos regionais brasileiros}

A análise do crédito rural, a partir de indicadores estatísticos de concentração e especialização, permite-nos uma maior aproximação quanto às condições de desenvolvimento regional, isto referente a uma das variáveis pouco analisadas em estudos nacionais, principalmente considerando os problemas de ordem federativa que se evidenciam no padrão regional de distribuição do crédito agrícola e pecuário.

\subsection{O padrão de distribuição do crédito agrícola brasileiro}

Vale denotar que o crédito rural sempre foi muito concentrado no país ${ }^{6}$, seja em termos regionais, seja em termos do acesso aos pequenos e médios produtores. Como observa estudo do Ipea (2010, p.367), quase "90\% das fazendas não relataram nenhum empréstimo de fontes formais ou informais no Censo de 1970, e essa proporção teria caído para 80\% [somente] em 1980". 0 mesmo estudo observa a importância da política recente referente à disseminação do Pronaf" que "saiu da modesta participação de 3,9 \% do valor total dos créditos em 1996, para aproximadamente $13 \%$ em 2008" (IPEA, 2010, p. 375).

6 As diferenciações regionais da agropecuária brasileira são ressaltadas por diversos estudos, por exemplo, Vieira Filho e Santos (2011) e Fornazier e Vieira Filho (2012) apontam a assimetria regional, destacando a heterogeneidade, seja no acesso à tecnologia ou na assistência técnica, ou mesmo nas "tecnologias sociais", como, o Fundo de Aval; conferir ainda Buianain e Garcia (2013).

7 A disseminação do Pronaf fez com que essa modalidade representasse quase $70 \%$ do número de contratos na oferta total de crédito rural formal (conferir Ipea, 2010). 
Tabela 3: $\mathrm{N}^{\circ}$ de contratos, valor total e média (crédito agrícola), em valores correntes, Brasil e regiões (2000/2010)

\begin{tabular}{|c|c|c|c|c|c|c|c|c|}
\hline \multirow{2}{*}{ Regiões } & \multicolumn{4}{|c|}{2000} & \multicolumn{4}{|c|}{2010} \\
\hline & $\begin{array}{c}\mathrm{N}^{\circ} \\
\text { Contratos }\end{array}$ & Valor & $\begin{array}{c}\text { Tamanho } \\
\text { Médio }\end{array}$ & $\begin{array}{c}\text { REG/ } \\
\text { BR }\end{array}$ & $\begin{array}{c}\mathbf{N}^{\circ} \\
\text { Contratos } \\
\end{array}$ & Valor & $\begin{array}{c}\text { Tamanho } \\
\text { Médio }\end{array}$ & $\begin{array}{c}\text { REG/ } \\
\text { BR }\end{array}$ \\
\hline Brasil & 1.086 .707 & 11.276 .871 .084 & 10.377 & 1,00 & 1.282 .160 & 57.886 .544 .083 & 45.148 & 1,00 \\
\hline $\begin{array}{l}\text { Região } \\
\text { NO }\end{array}$ & 62.003 & 301.881 .921 & 4.869 & 0,46 & 36.523 & 763.010 .632 & 20.891 & 0,46 \\
\hline $\begin{array}{l}\text { Região } \\
\text { NE }\end{array}$ & 160.765 & 672.067 .818 & 4.180 & 0,40 & 185.047 & 5.536 .460 .779 & 29.919 & 0,66 \\
\hline $\begin{array}{l}\text { Região } \\
\text { CO }\end{array}$ & 39.361 & 1.773 .058 .722 & 45.046 & 4,34 & 41.202 & 7.577.419.567 & 183.909 & 4,07 \\
\hline $\begin{array}{l}\text { Região } \\
\text { SUL }\end{array}$ & 655.612 & 4.955 .471 .693 & 7.559 & 0,72 & 744.520 & 24.137.631.458 & 32.420 & 0,71 \\
\hline $\begin{array}{l}\text { Região } \\
\text { SE }\end{array}$ & 168.966 & 3.574 .390 .930 & 21.154 & 2,03 & 274.868 & 19.872 .021 .647 & 72.297 & 1,60 \\
\hline
\end{tabular}

Fonte: Bacen, 2000-2010. Elaboração dos autores.

0 perfil do crédito agrícola a partir da média contratual nos revela alguns pontos importantes sobre o desenvolvimento recente (na última década) da distribuição do crédito rural em nível nacional. Primeiro ponto a se destacar diz respeito ao valor médio dos contratos firmados, do qual a Região Centro-Oeste é de longe a que detém os maiores contratos, sendo que os tamanhos médios dos empréstimos regionais são mais de quatro vezes o padrão médio nacional, seja para 2000, quanto para 2010. Vale notar que a região Sul, que concentra o maior volume de crédito agrícola, apresenta a maior dispersão, retendo um maior número de contratos e de valor médio inferior, o que refletirá como veremos, nos indicadores de participação relativa. A evolução do padrão agrícola brasileiro nas décadas de 1990 e 2000, quando a importância da região Centro-Oeste se estabelece na condição de nova fronteira de produção de cereais para exportação, principalmente soja e milho, coaduna com o padrão de crédito mais concentrado observado naquela região. 
Tabela 4: Participação relativa das regiões no crédito agrícola e PIB agropecuário, em valores correntes, (2000/2010)

\begin{tabular}{c|c|c|c|c|c|c|c|c}
\hline \multirow{2}{*}{ Regiões } & \multicolumn{5}{|c|}{$\mathbf{2 0 0 0}$} & \multicolumn{4}{c}{$\mathbf{2 0 1 0}$} \\
\cline { 2 - 10 } & Crédito & \multicolumn{1}{|c|}{$\%$} & PIB & \% & Crédito & \% & PIB & \% \\
\hline Brasil & 11.276 .871 .084 & 100,0 & $57.241 .000,00$ & 100,0 & 57.886 .544 .083 & 100,0 & $171.177 .392,00$ & 100,0 \\
\hline Região NO & 301.881 .921 & 2,7 & $4.701 .360,01$ & 8,2 & 763.010 .632 & 1,3 & $17.097 .349,52$ & 10,0 \\
\hline Região NE & 672.067 .818 & 6,0 & $10.781 .058,98$ & 18,8 & 5.536 .460 .779 & 9,6 & $29.356 .220,79$ & 17,1 \\
\hline Região CO & 1.773 .058 .722 & 15,7 & $9.009 .484,38$ & 15,7 & 7.577 .419 .567 & 13,1 & $29.857 .539,29$ & 17,4 \\
\hline Região SUL & 4.955 .471 .693 & 43,9 & $17.854 .160,36$ & 31,2 & 24.137 .631 .458 & 41,7 & $51.214 .338,41$ & 29,9 \\
\hline Região SE & 3.574 .390 .930 & 31,7 & $14.894 .936,27$ & 26,0 & 19.872 .021 .647 & 34,3 & $43.651 .943,99$ & 25,5 \\
\hline
\end{tabular}

Fonte: Bacen, 2000-2010. Elaboração dos autores.

A Tabela 4 apresentada nos fornece um quadro da evidente concentração do volume de crédito agrícola na Região Sul, seja contratualmente, seja em medida de valor. Historicamente, a região Sul centraliza a maior capacidade de produção agrícola, o que se correlaciona com essa maior dotação de crédito, seguido muito de perto, em termos de valor, da região Sudeste. Vale observar, porém, que o volume de recursos apresenta uma dispersão bem maior no Sul e Nordeste (NE), do que nas regiões Sudeste (SE) e Centro-Oeste (CO). Essa última região, a exemplo do padrão médio superior, também denota significativa menor dispersão do crédito, reforçando o entendimento de que sua base agrícola, tomadora de crédito, é mais concentrada em empreendimentos de maior porte. Os dados também demonstram o perfil evolutivo do volume de crédito agrícola, apontando que em dez anos o crescimento real médio anual no Brasil foi superior a $90 \%$, sendo que em algumas regiões observa-se uma explosiva taxa de crescimento, e a maior concentrando-se na região Nordeste, que cresce anualmente acima de $160 \%$, evidenciando, assim, que o crédito agrícola correspondeu a um forte estimulador da economia nordestina nesse período.

Os dados comparativos de participação relativa no PIB agropecuário sugere-nos um comportamento que reforça a análise desenvolvida em estudos como os de Kumar (2004); Gasque et al (2004) e Ipea (2010), referentes à correlação entre crédito e crescimento do PIB agropecuário. Observa-se que, exceto no caso das Regiões Norte e Sudeste, PIB e crédito apresentam tendência de participação relativa regional aproximada. Vale notar que as regiões Sul e 
Sudeste cedem magnitude relativa para as demais, especialmente o Centro Oeste, sendo que o Norte apresenta crescimento em sua participação relativa no PIB nacional, mesmo frente a um forte declínio relativo na disponibilidade de crédito.

Com base no ICn e na metodologia já exposta, observa-se que os municípios com "elevada disponibilidade" de crédito agrícola cresce em quase 60\% no período de uma década, observando-se, também, uma maior disseminação do crédito com expressiva redução dos municípios que "não acessavam" crédito (o tipo "D" reduz de 862 para 295); porém as municipalidades com "precário acesso" (tipos C1 e C2) aumentam em aproximadamente 48\%, o que implica que municípios que tinham mediana disponibilidade de crédito agrícola tiveram suas condições pioradas no período.

\section{Gráfico 1: Padrão de distribuição do crédito agrícola}

(ICn Valor) (\%) - Brasil (2000/2010)

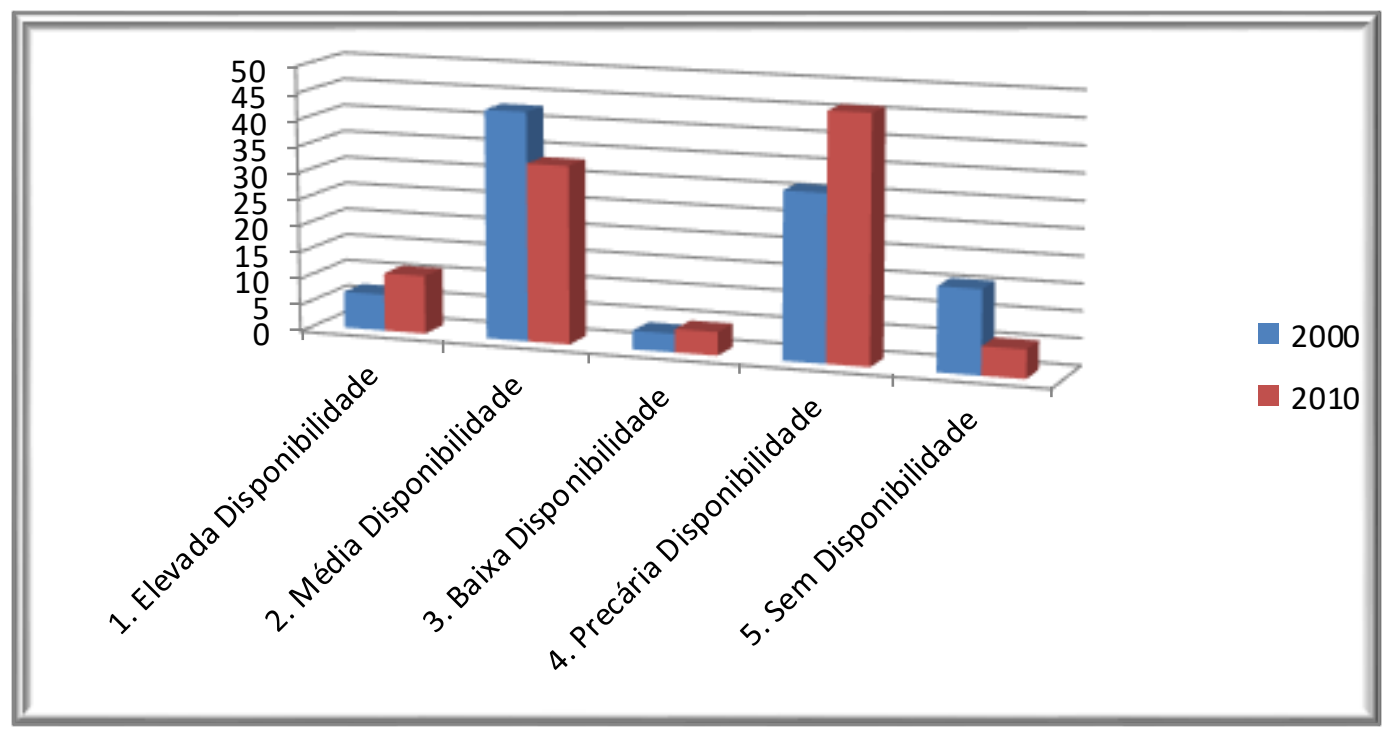

Fonte: Bacen, 2000-2010. Elaboração dos autores.

4.2 Análise regional dos indicadores e o padrão tipológico do crédito agrícola brasileiro

A seguir analisamos de forma regionalizada o comportamento do crédito agrícola, centrado na tipologia proposta e nos indicadores de especialização enunciados na metodologia. A primeira observação geral refere-se ao padrão tipológico estruturado, os municípios dos Tipos A1 e A2 estão em grande maioria localizados no Sul e Sudeste do país, padrão este que é reforçado pelos níveis dos 
indicadores de especialização, especificamente o CEi (Coeficiente de Especialização) e o IKi (Indice de Krugman), que como se verá, apresentam para os municípios do Norte e Nordeste valores muito superiores ao padrão nacional, indicando duas possibilidades: i) ausência ou baixa dotação de crédito; ii) somente linha de crédito especializada (crédito destinado a investimento) e circunstancial. No caso dos municípios do Sul, Sudeste e Centro-Oeste, em menor grau, os indicadores são próximos a zero, denotando maior diversificação do crédito (custeio, comercialização e investimento).

Tabela 5: Distribuição regional dos municípios de elevada disponibilidade de crédito agrícola $(2000 / 2010)$

\begin{tabular}{c|c|c|c|c|c|c|c|c}
\hline \multirow{2}{*}{ REGIÃO } & \multicolumn{4}{|c|}{$\mathrm{N}^{\circ}$ Municípios (2000) } & \multicolumn{4}{c}{$\mathrm{N}^{\circ}$ Municípios (2010) } \\
\cline { 2 - 9 } Norte & A1 & A2 & Total & $(\%)$ & A1 & A2 & Total & $(\%)$ \\
\hline \multirow{2}{*}{ Nordeste } & 2 & 2 & 2 & 0,5 & 1 & 3 & 4 & 0,7 \\
Centro Oeste & 13 & 22 & 35 & 9,3 & 16 & 42 & 58 & 9,7 \\
Sul & 44 & 125 & 169 & 45,1 & 144 & 164 & 308 & 51,2 \\
Sudeste & 41 & 118 & 159 & 42,4 & 48 & 148 & 196 & 32,6 \\
\hline Brasil & 100 & 275 & 375 & 100,0 & 216 & 385 & 601 & 100,0 \\
\hline
\end{tabular}

Fonte: Bacen, 2000-2010. Elaboração dos autores.

Os dados acima expostos mostram que aproximadamente 84\% dos municípios com elevada disponibilidade de crédito agrícola estão concentrados no Sul e Sudeste em 2010, sendo irrisória a participação da Região Norte, cuja evolução entre os indicadores de 2000 para 2010 foram insignificantes (passou de 0,5\% para 0,7\%). Esse quadro é parcialmente diverso em relação ao Nordeste, que nas últimas duas décadas teve uma sensível melhora, crescendo sua participação nacional no crédito agrícola de forma significativa, por mais que ainda detenha menos de $6 \%$ do crédito nacionalmente ofertado. Por último, o Centro-Oeste demonstra que se firmou como efetiva frente de expansão agrícola, avançando, paulatinamente, para tornar-se principal espaço econômico agropecuário nacional, por mais que ainda não detenha o mesmo nível de disponibilidade creditícia que o Sul e Sudeste. 
A comparação dos números referentes à participação no volume de crédito por região evidencia certa estabilidade na participação inter-regional. Em 2000, as Regiões Sul e Sudeste detinham, conjuntamente, cerca de $57,2 \%$ do volume total, caindo em 2010 para 55,4\%. Considerando a tipologia utilizada, podemos deduzir que essa pequena desconcentração se deveu à maior participação dos municípios dos tipos A3 e B1, principalmente nas regiões periféricas, novamente o destaque para o Nordeste.

A Tabela 6, seguinte, reforça a análise anterior, em dois aspectos importantes para nortear futuras políticas públicas: i) as municipalidades de média disponibilidade são menos concentradas nas regiões Sul e Sudeste, apresentando maior presença no Nordeste e Norte. Como se nota na tabela, por mais que se mantenha a enorme concentração nestas faixas (cerca de $70 \%$ ), as demais regiões conseguem deter $25 \%$ do volume de crédito disponibilizado. Pode-se buscar uma possível explicação para isso nos recursos provenientes dos Fundos Constitucionais (FNE, FCO e FNO), que passaram a viabilizar linhas de crédito agrícola direcionados para as referidas regiões; ii) uma segunda linha de explicação relaciona-se ao Pronaf que, como já antes exposto, tem um caráter mais inclusivo e apresenta um perfil mais disseminador de pequenos e médios contratos, o que favorece especialmente o Nordeste. Os aspectos elencados reforçam a importância de políticas públicas que combinem ações proativas como o Pronaf, com a formalização de uma rede institucional que integre as municipalidades dessa tipologia na coordenação das políticas de crédito gestoras dos Fundos Constitucionais, assim como o aperfeiçoamento dos chamados Fundos de $\mathrm{Aval}^{8}$, algo que se tratará nas considerações finais e proposições.

8 Os fundos de avais são complementos às garantias exigidas pelos bancos; os fundos municipais ou estaduais são criados mediante lei, tendo como objetivo oferecer aval a pequenos e microprodutores (posseiros, meeiros, arrendatários) que não possam oferecer as garantias exigidas pelas instituições financeiras. 
Tabela 6: Distribuição regional dos municípios de média e baixa disponibilidade de crédito agrícola $(2000 / 2010)$

\begin{tabular}{c|c|c|c|c|c|c} 
REGIÃO & A3+B1 & $(\%)$ & B2+B3 & $(\%)$ & C1+C2+D & $(\%)$ \\
\hline \multicolumn{7}{c|}{$\mathrm{N}^{\circ}$ Municípios $(2000)$} \\
\hline Norte & 56 & 2,4 & 4 & 2,1 & 387 & 15,0 \\
\hline Nordeste & 572 & 24,2 & 22 & 11,5 & 1181 & 45,8 \\
\hline Centro Oeste & 118 & 5,0 & 12 & 6,3 & 281 & 10,9 \\
\hline Sul & 785 & 33,3 & 69 & 35,9 & 136 & 5,3 \\
\hline Sudeste & 828 & 35,1 & 85 & 44,3 & 594 & 23,0 \\
\hline Brasil & 2359 & 100,0 & 192 & 100,0 & 2579 & 100,0 \\
\hline \multicolumn{7}{|c|}{$\mathrm{N}^{\circ}$ Municípios $(2010)$} \\
\hline Norte & 82 & 4,5 & 10 & 4,1 & 354 & 13,3 \\
\hline Nordeste & 334 & 18,2 & 29 & 12,0 & 1222 & 45,9 \\
\hline Centro Oeste & 89 & 4,9 & 19 & 7,9 & 279 & 10,5 \\
\hline Sul & 590 & 32,2 & 84 & 34,9 & 178 & 6,7 \\
\hline Sudeste & 738 & 40,3 & 99 & 41,1 & 632 & 23,7 \\
\hline Brasil & 1833 & 100,0 & 241 & 100,0 & 2665 & 100,0 \\
\hline
\end{tabular}

Fonte: Bacen, 2000-2010. Elaboração dos autores.

Figura 1: Tipologia do crédito agrícola com base no ICn do valor do crédito agrícola para custeio, comercialização e investimento, 2000.

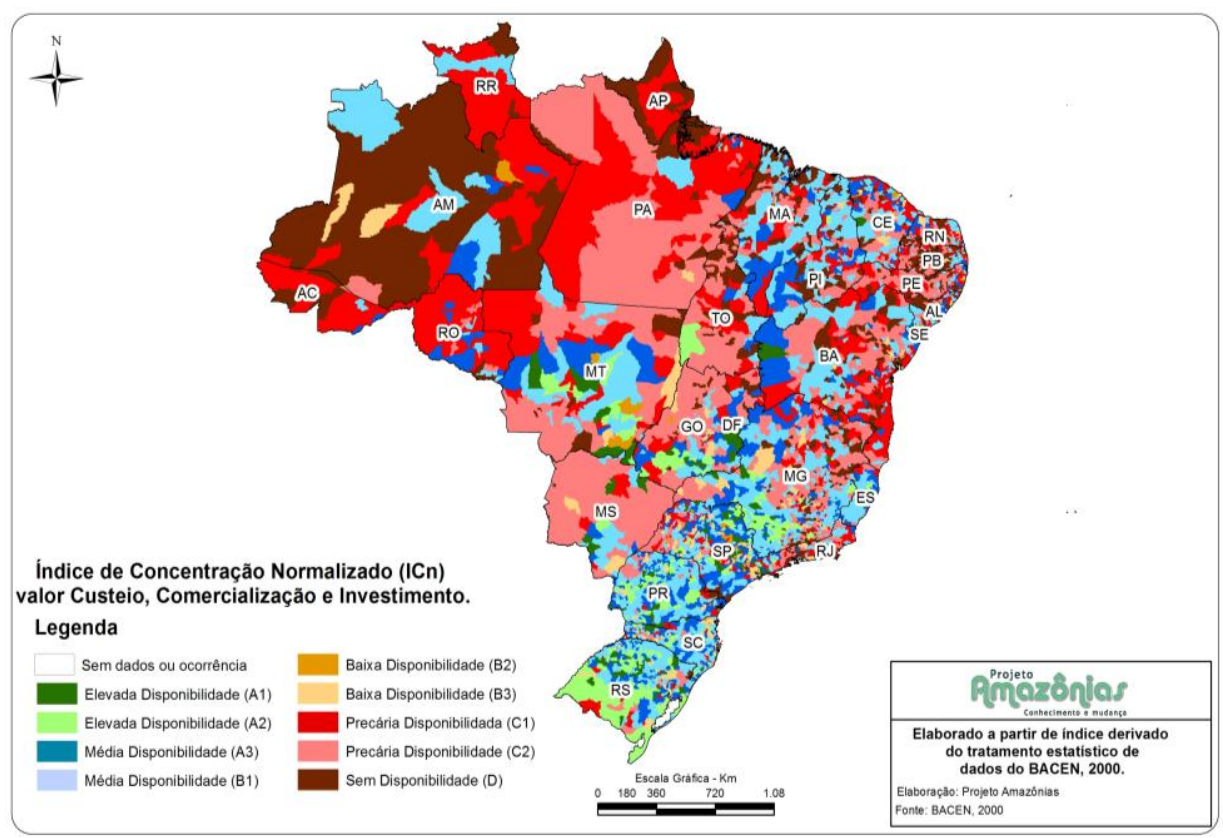

Fonte: BACEN, 2000. 
Figura 2: Tipologia do crédito agrícola com base no ICn do valor do crédito agrícola para custeio, comercialização e investimento, 2010.

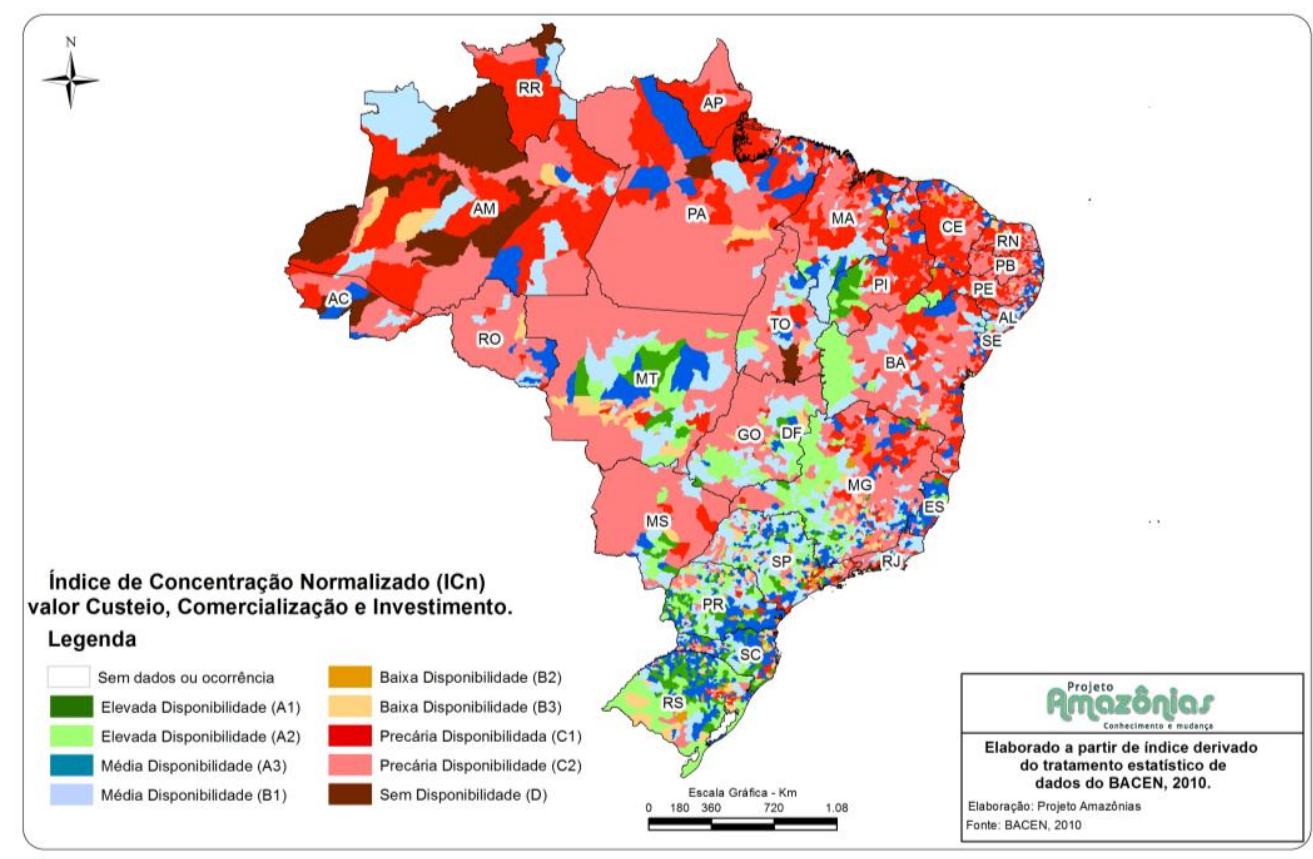

Fonte: BACEN, 2010.

Os dados referentes aos municípios em piores condições de disponibilidade de crédito reforçam a percepção já apontada de maior dispersão do crédito, o que se verifica com a diminuição expressiva dos municípios que não acessam crédito de nenhuma forma. Esses dados denotam, ainda, a precariedade da disponibilidade do crédito agrícola, pois mais da metade das municipalidades $(55,81 \%)$ está classificada nas faixas B2, B3, C1, C2 e D, ou seja, ou não há disponibilidade creditícia, ou sua disponibilidade é precária ou baixa (conferir as Tabelas 9 e 10 abaixo).

Aspecto regional a ser reforçado diz respeito a maior concentração dos municípios de precária ou inexistente disponibilidade estarem localizados nas regiões Norte e Nordeste (conferir Tabela 8), o que reforça a importância de se pensar novas políticas públicas regionalizadas para disponibilização do crédito agrícola, o que deverá ser coordenado com o aperfeiçoamento das linhas de crédito já existentes, especialmente os Fundos Constitucionais e o Pronaf.

A análise regional mais específica pode ser feita a partir dos indicadores de especialização, sendo possível caracterizar melhor as condições de disponibilidade creditícia, bem como o grau de especialização. A Região Norte pode ser melhor 
tipificada observando-se o elevado CEi (Coeficiente de Especialização) das municipalidades em geral, inclusive daquelas que apresentam o melhor padrão tipológico (Tabela 7), o que implica que as condições de crédito na região são, além de precárias em termos de disponibilidade, bastante concentradas em um único tipo de crédito. Isto é reforçado pelos indicadores de desigualdade (CVi) que se apresentam bem acima da média nacional $(0,95)$ e muito acima de zero. Por sua vez, o coeficiente de reestruturação (Cri) nos mostra que entre 2000 e 2010 houve alguma alteração positiva no padrão de crédito rural, porém, observa-se que a maioria dos municípios apresenta um coeficiente acima da média nacional de 0,18 (conferir Tabela 3), implicando que o padrão do crédito rural agrícola da Região Norte ainda se mantém aquém do padrão nacional.

Tabela 7: Índices de concentração, especialização e desigualdade dos cinco municípios da Região Norte, com melhor disponibilidade de crédito agrícola $(2000 / 2010)$

\begin{tabular}{|c|c|c|c|c|c|c|c|c|c|}
\hline Estado & Município & $\begin{array}{c}\text { ICNik } \\
\text { Cust }\end{array}$ & $\mathrm{CEi}$ & $\mathrm{ENi}$ & IKi & IBDRi & $\mathrm{CVi}$ & Cri & Tipologia \\
\hline \multicolumn{10}{|c|}{2000} \\
\hline $\mathrm{AM}$ & Carauari & 0,392 & 0,762 & 0,474 & 1,524 & 5,492 & 1,39 & 0,44 & $\mathrm{~A} 2$ \\
\hline TO & $\begin{array}{c}\text { Formoso do } \\
\text { Araguaia }\end{array}$ & 0,347 & 0,657 & 0,594 & 1,314 & 5,672 & 1,65 & 0,23 & $\mathrm{~A} 2$ \\
\hline RO & $\begin{array}{c}\text { Alta Floresta } \\
\text { D'Oeste }\end{array}$ & 0,428 & 0,157 & 0,668 & 0,315 & 5,759 & 1,78 & 0,14 & A3 \\
\hline RO & Colorado do Oeste & 0,303 & 0,181 & 0,729 & 0,362 & 5,788 & 1,69 & 0,27 & A3 \\
\hline RO & Costa Marques & 0,274 & 0,137 & 0,522 & 0,274 & 5,575 & 1,23 & 0,32 & A3 \\
\hline \multicolumn{10}{|c|}{2010} \\
\hline TO & Lagoa da Confusão & 0,26612 & 0,208 & 0,355 & 0,417 & 5,194 & 1,20 & 0,15 & $\mathrm{~A} 2$ \\
\hline TO & Centenário & 0,1679 & 0,223 & 0,289 & 0,446 & 5,058 & 0,92 & 0,11 & $\mathrm{~A} 2$ \\
\hline TO & Itapiratins & 0,21354 & 0,151 & 0,236 & 0,303 & 4,941 & 0,82 & 0,25 & $\mathrm{~A} 2$ \\
\hline PA & Peixe-Boi & 0 & 0,456 & 0,704 & 0,913 & 5,777 & 0,78 & 0,38 & A3 \\
\hline TO & Lagoa do Tocantins & 0,00042 & 0,386 & 0,56 & 0,772 & 5,633 & 1,31 & 0,35 & A3 \\
\hline
\end{tabular}

Fonte: Bacen, 2000-2010. Elaboração dos autores.

No caso da Amazônia Legal, os municípios dos estados de Rondônia e Tocantins fogem a essa caracterização geral da Região Norte. No caso de Rondônia, o Coeficiente de Especialização, combinado com o Índice de Entropia (ENi) mais baixo indica que diversas municipalidades desse estado (Alta Floresta do Oeste e Ariquemes, por 
exemplo) são fortes atrativos de crédito agrícola, o que converge para torná-lo frente natural de expansão agrícola, movimento já observado na sua produção.

A Região Nordeste apresenta um perfil em franca alteração, porém, ainda apresentando indicadores bastante desfavoráveis. Primeiro aspecto a ser observado refere-se à alteração do padrão médio entre 2000 e 2010 (Tabela 8 e Figuras 1 e 2). A região passa a deter a partir de 2010 diversos municípios do padrão $\mathrm{A} 1$, o que é significativo em termos da mencionada dispersão do crédito em nível nacional. Entretanto os elevados indicadores de especialização e entropia apontam baixa diversificação do crédito, o que implica que a disponibilidade de crédito está ligada a linhas muito específicas (caso dos recursos ligados ao Fundo Constitucional do Nordeste) e, provavelmente, muito vinculada aos recentes setores de produção de fruticultura. Vale observar que vários municípios do Piauí aparecem em boas condições de disponibilidade creditícia, algo a ser verificado mais de perto, mas pode-se observar uma paulatina ocupação da área da chamada "Gurgeia", já na entrada do corredor amazônico. ${ }^{9}$

Tabela 8: Índices de concentração, especialização e desigualdade dos cinco municípios da Região Nordeste, com melhor disponibilidade de crédito agrícola $(2000 / 2010)$

\begin{tabular}{|c|c|c|c|c|c|c|c|c|c|}
\hline Estado & Município & ICNik & CEi & ENi & IKi & IBDRi & CVi & CRi & Tipologia \\
\hline \multicolumn{10}{|c|}{2000} \\
\hline CE & Crateús & 0,275 & 0,211 & 0,818 & 0,422 & 5,901 & 0,81 & 0,17 & $\mathrm{~A} 1$ \\
\hline BA & Barreiras(*) & 0,429 & 0,189 & 0,534 & 0,378 & 5,586 & 0,38 & 0,11 & $\mathrm{~A} 1$ \\
\hline PB & Bayeux & 0,333 & 0,988 & 1 & 1,975 & 6 & 0 & 0,55 & $\mathrm{~A} 2$ \\
\hline PI & $\operatorname{Altos}(*)$ & 0,3 & 0,295 & 0,99 & 0,59 & 5,997 & 0,03 & 0,36 & A2 \\
\hline CE & Quixeramobim & 0,468 & 0,244 & 0,853 & 0,489 & 5,913 & 1,59 & 0,33 & $\mathrm{~A} 2$ \\
\hline \multicolumn{10}{|c|}{2010} \\
\hline PI & $\begin{array}{c}\text { Baixa Grande do } \\
\text { Ribeiro }\end{array}$ & 0,5 & 0,397 & 0,532 & 0,794 & 5,571 & 1,16 & 0,3 & $\mathrm{~A} 1$ \\
\hline PI & Uruçuí & 0,54 & 0,344 & 0,504 & 0,689 & 5,549 & 1,42 & 0,19 & $\mathrm{~A} 1$ \\
\hline PI & $\begin{array}{c}\text { Monte Alegre do } \\
\text { Piauí }\end{array}$ & 0,29 & 0,336 & 0,363 & 0,673 & 5,161 & 0,95 & 0,14 & $\mathrm{~A} 1$ \\
\hline MA & Sambaíba & 0,55 & 0,31 & 0,48 & 0,62 & 5,48 & 1,43 & 0,21 & A1 \\
\hline PI & Currais & 0,52 & 0,334 & 0,488 & 0,668 & 5,518 & 1,15 & 0,21 & $\mathrm{~A} 1$ \\
\hline
\end{tabular}

Fonte: Bacen, 2000-2010. Elaboração dos autores.

9 Segundo estudo de Gasques et al (2004), o Banco do Nordeste do Brasil (BNB) financia 90\% das operações da região e a principal fonte de financiamento usada é o Fundo Constitucional de Financiamento do Nordeste (FNE) que, segundo aquele estudo, tem sido bastante direcionado para a fruticultura, cujo custo de implantação da lavoura é muito elevado, sendo que mesmo os recursos provenientes do referido fundo têm sido insuficientes para suprir às necessidades dessa frente de expansão do capital. 
O padrão observado no Centro-Oeste (Tabela 9) é muito distinto das duas regiões anteriores, sendo que se pode destacar três pontos importantes na análise regional: i) primeiramente a tipologia padrão é da presença maior de municípios com mais disponibilidade de crédito, sendo que Mato Grosso apresenta uma forte preponderância; ii) a região é mais homogênea, sendo que tanto Goiás quanto o Mato Grosso do Sul apresentam padrões acima da média nacional (ver Tabela 3); iii) os coeficientes de especialização e entropia são mais próximos de zero, o que define, por um lado, maior grau de diversificação do crédito e, por outro lado, maior equilíbrio na demanda por diferentes tipos de crédito, próprio de uma estrutura de produção agrícola mais avançada sob o ponto de vista das relações de produção capitalistas.

Tabela 9: Índices de concentração, especialização e desigualdade dos cinco municípios da região Centro-Oeste com melhor disponibilidade de crédito agrícola $(2000 / 2010)$

\begin{tabular}{|c|c|c|c|c|c|c|c|c|c|}
\hline Estado & Município & $\begin{array}{c}\text { ICNik } \\
\text { Cust }\end{array}$ & CEi & $\mathrm{ENi}$ & $\mathrm{IKi}$ & IBDRi & $\mathrm{CVi}$ & Cri & Tipologia \\
\hline \multicolumn{10}{|c|}{2000} \\
\hline MT & Nova Ubiratã & 0,388 & 0,293 & 0,35 & 0,585 & 5,246 & 1,48 & 0,22 & $\mathrm{~A} 1$ \\
\hline GO & $\begin{array}{c}\text { Santa Fé de } \\
\text { Goiás }\end{array}$ & 0,306 & 0,5 & 0,269 & 1,001 & 5,044 & 1,13 & 0,12 & A1 \\
\hline MT & $\begin{array}{c}\text { Campo Novo } \\
\text { do Parecis }\end{array}$ & 0,351 & 0,126 & 0,527 & 0,251 & 5,509 & 1,82 & 0,14 & $\mathrm{~A} 1$ \\
\hline MT & Itiquira & 0,42 & 0,245 & 0,201 & 0,489 & 4,879 & 1,5 & 0,12 & $\mathrm{~A} 1$ \\
\hline MT & Guiratinga & 0,348 & 0,459 & 0,203 & 0,918 & 4,888 & 1,19 & 0,18 & $\mathrm{~A} 1$ \\
\hline \multicolumn{10}{|c|}{2010} \\
\hline GO & $\begin{array}{c}\text { Chapadão do } \\
\text { Céu }\end{array}$ & 0,54 & 0,307 & 0,484 & 0,615 & 5,501 & 1,4 & 0,22 & $\mathrm{~A} 1$ \\
\hline MT & Sapezal & 0,52 & 0,386 & 0,541 & 0,775 & 5,592 & 1,41 & 0,17 & $\mathrm{~A} 1$ \\
\hline MT & Nova Ubiratã & 0,5 & 0,291 & 0,452 & 0,583 & 5,448 & 1,3 & 0,22 & $\mathrm{~A} 1$ \\
\hline MT & Santa Carmem & 0,47 & 0,256 & 0,357 & 0,512 & 5,262 & 1,17 & 0,11 & $\mathrm{~A} 1$ \\
\hline MT & $\begin{array}{c}\text { Primavera do } \\
\text { Leste }\end{array}$ & 0,46 & 0,258 & 0,38 & 0,518 & 5,319 & 1,33 & 0,14 & $\mathrm{~A} 1$ \\
\hline
\end{tabular}

Fonte: Bacen, 2000-2010. Elaboração dos autores.

Considerando-se um padrão de "elevada diversidade" na faixa até 0,413 do ENi para 2000 e 0,310 para 2010, observa-se que a maior parte dos municípios do Tipo A1 estão nessa faixa (ver Quadro 2). Essa maior diversidade também se observa no Índice de Krugman (IKi), o que reforça a condição regional de maior 
frente de expansão do agronegócio brasileiro, confirmada pela forte evolução do PIB agropecuário dessas municipalidades e da participação regional no PIB nacional.

Vale destacar que Mato Grosso concentra aproximadamente $30 \%$ da produção brasileira de soja, e de acordo com o último Censo (2006), a distribuição da terra por classe de área é uma das mais concentradas nacionalmente: "68\% dos estabelecimentos possuem menos de 100 ha, e ocupam 5,5\% da área; 23,5\% estão situados na classe de área que varia de 100 a $1 \mathrm{mil} \mathrm{ha,} \mathrm{ocupando} 17 \%$ da área; e, por fim, as unidades acima de $1 \mathrm{mil} \mathrm{ha,} \mathrm{que} \mathrm{representa} \mathrm{7,6 \%} \mathrm{dos} \mathrm{estabelecimentos,}$ ocupam 77,5\% da área total recenseada" (Ipea, 2013). De uma maneira geral, entende-se que a expansão da frente de acumulação capitalista, centrada na produção de "commodities" agrícolas, tem como um dos pontos de apoio a maior disponibilidade de crédito e a diversificação da oferta do mesmo.

As regiões Sul e Sudeste concentram, classicamente, o crédito agrário, apresentando os menores coeficientes de especialização, mesmo que, curiosamente, os indicadores de Entropia Normalizada e Krugman sejam superiores aos do CentroOeste. A possível explicação estaria na maior concentração de custeio requerida pela estrutura de produção mais antiga dessas regiões. De maneira geral, os gastos com investimento estão mais presentes nas áreas de expansão da lavoura, uma vez que o crédito destinado à comercialização aparece como segundo item após o custeio nessas regiões de produção mais antigas.

Tabela 10: Índices de concentração, especialização e desigualdade dos cinco municípios da região Sudeste com melhor disponibilidade de crédito agrícola (2000/2010)

\begin{tabular}{c|c|c|c|c|c|c|c|c|c|c}
\hline Estado & Município & $\begin{array}{r}\text { ICNik } \\
\text { Cust }\end{array}$ & CEi & ENi & IKi & IBDRi & CVi & CRi & Tipologia \\
\hline \multicolumn{1}{|c}{2000} \\
\hline SP & Lençóis Paulista & 0,44 & 0,398 & 0,228 & 0,797 & 4,961 & 1,77 & 0,28 & A1 \\
MG & Coromandel & 0,427 & 0,192 & 0,397 & 0,384 & 5,339 & 1,39 & 0,07 & A1 \\
MG & Cristais & 0,489 & 0,229 & 0,823 & 0,459 & 5,891 & 1,69 & 0,04 & A1 \\
ES & Itaguaçu & 0,379 & 0,222 & 0,798 & 0,443 & 5,854 & 2,01 & 0,12 & A1 \\
MG & Campos Gerais & 0,513 & 0,274 & 0,81 & 0,548 & 5,896 & 1,97 & 0,13 & A1 \\
\hline \multicolumn{7}{|c|}{2010} \\
SP & Caconde & 0,59 & 0,368 & 0,551 & 0,736 & 5,602 & 1,58 & 0,13 & A1 \\
MG & Conceição da Aparecida & 0,59 & 0,364 & 0,557 & 0,729 & 5,625 & 1,57 & 0,14 & A1 \\
SP & Buri & 0,58 & 0,37 & 0,553 & 0,74 & 5,621 & 1,56 & 0,19 & A1 \\
MG & Itamogi & 0,56 & 0,372 & 0,54 & 0,745 & 5,609 & 1,5 & 0,11 & A1 \\
SP & Pitangueiras & 0,56 & 0,325 & 0,478 & 0,65 & 5,462 & 1,46 & 0,22 & A1 \\
\hline
\end{tabular}

Fonte: Bacen, 2000-2010. Elaboração dos autores. 
O coeficiente de variação (CVi) apresenta-se relativamente elevado, demonstrando a concentração em pelo menos dois tipos de crédito, o que corresponde ao quadro das estatísticas desagregadas e da maior incidência dos créditos de custeio e comercialização. 0 coeficiente de reestruturação (CR) aponta a estabilidade das condições médias de demanda de crédito nas duas regiões: na sua quase totalidade as municipalidades tomadas como bechmark apresentam indicadores inferiores ao padrão médio brasileiro e próximo de zero, sinalizando a manutenção do perfil creditício rural agrícola na década.

Tabela 11: Índices de concentração, especialização e desigualdade dos cinco municípios da região Sul com melhor disponibilidade de crédito agrícola $(2000 / 2010)$

\begin{tabular}{|c|c|c|c|c|c|c|c|c|c|}
\hline Estado & Município & $\begin{array}{c}\text { ICNik } \\
\text { Cust }\end{array}$ & CEi & $\mathrm{ENi}$ & $\mathrm{IKi}$ & IBDRi & $\mathrm{CVi}$ & CRi & Tipologia \\
\hline \multicolumn{10}{|c|}{2000} \\
\hline $\mathrm{RS}$ & Nova Pádua & 0,494 & 0,281 & 0,948 & 0,563 & 5,978 & 1,55 & 0,11 & A1 \\
\hline PR & Londrina & 0,421 & 0,185 & 0,707 & 0,371 & 5,738 & 1,73 & 0,13 & $\mathrm{~A} 1$ \\
\hline PR & $\begin{array}{c}\text { Boa Ventura de São } \\
\text { Roque }\end{array}$ & 0,288 & 0,212 & 0,687 & 0,424 & 5,761 & 1,26 & 0,13 & $\mathrm{~A} 1$ \\
\hline $\mathrm{RS}$ & Muitos Capões & 0,367 & 0,165 & 0,672 & 0,331 & 5,737 & 1,94 & 0,09 & $\mathrm{~A} 1$ \\
\hline RS & Caibaté $(*)$ & 0,331 & 0,153 & 0,657 & 0,307 & 5,726 & 1,61 & 0,08 & $\mathrm{~A} 1$ \\
\hline \multicolumn{10}{|c|}{2010} \\
\hline PR & São Mateus do Sul & 0,58 & 0,406 & 0,6 & 0,812 & 5,688 & 1,59 & 0,12 & A1 \\
\hline SC & Maracajá & 0,57 & 0,387 & 0,565 & 0,774 & 5,642 & 1,54 & 0,11 & $\mathrm{~A} 1$ \\
\hline $\mathrm{SC}$ & Urubici & 0,55 & 0,343 & 0,5 & 0,686 & 5,536 & 1,45 & 0,09 & $\mathrm{~A} 1$ \\
\hline SC & Sombrio & 0,55 & 0,387 & 0,565 & 0,773 & 5,632 & 1,48 & 0,16 & A1 \\
\hline PR & Ourizona & 0,55 & 0,323 & 0,533 & 0,646 & 5,563 & 1,24 & 0,13 & $\mathrm{~A} 1$ \\
\hline
\end{tabular}

Fonte: Bacen, 2000-2010. Elaboração dos autores.

\section{Considerações finais}

O debate referente ao crédito rural brasileiro tem sido, muitas vezes, centrado na relação entre a capacidade de subsídio creditício disponibilizado pelos bancos públicos e seus reflexos sobre a base de crescimento do PIB agropecuário. As bases teóricas tratadas em grande medida vinculam-se à percepção de neutralidade monetária, o que supõe o crédito como um simples fator deslocador de potencial produtivo intersetorial. 
A análise desenvolvida neste trabalho utilizou-se de um conjunto de indicadores para tratar, em um primeiro nível inter-regional, das condições de disponibilidade de crédito e, em segundo nível, do perfil brasileiro do crédito rural. Teoricamente apoiamo-nos na análise de crédito como componente sistêmico da reprodução capitalista, este funcionando na qualidade de fator resultante, e ainda estimulador da dinâmica de acumulação. Assim, tendo como base a análise de indicadores regionais, um padrão tipológico do crédito rural (agrícola e pecuária) estabelece-se a partir de elementos para tratar as políticas de crédito, considerando as especificidades locais.

Nesse sentido, convém reforçar alguns pontos já observados ao longo da análise desenvolvida:

i) No Brasil, o sistema de crédito à agricultura e à pecuária é, em larga escala, centrado nas instituições financeiras públicas, porém com alguma participação das instituições bancárias privadas e outras modalidades de financiamento. 0 crédito rural no Brasil tem uma dupla face: é em grande medida ofertado por instituições públicas, centrado, inclusive, em programas constitucionalizados ou historicamente enraizados; segundo, é fortemente concentrado no Sul e $\underline{\text { Sudeste }}$ do país.

ii) Os indicadores mostram que aproximadamente $84 \%$ dos municípios com elevada disponibilidade de crédito agrícola estão concentrados no Sul e Sudeste em 2010, sendo irrisória a participação da região Norte, cuja evolução entre os indicadores de 2000 para 2010 foram insignificantes (passaram de 0,5\% para $0,7 \%$ ). Nesse contexto, é nas regiões Norte e Nordeste que se dá a maior concentração dos municípios de precária ou inexistente disponibilidade creditícia, o que reforça a importância de se pensar novas políticas públicas regionalizadas de oferta de crédito agrícola, o que deverá ser coordenado com o aperfeiçoamento das linhas de crédito já existentes, especialmente os Fundos Constitucionais e o Pronaf.

iii) Os indicadores demonstram, ainda, que o Centro-Oeste se firmou como efetiva frente de expansão agrícola, avançando, paulatinamente, para se firmar como principal espaço econômico agropecuário nacional, embora não detenha o mesmo nível de disponibilidade creditícia que o Sul e Sudeste. Três elementos de caracterização regional são componentes peculiares do CentroOeste com particular influência do estado do Mato Grosso: a) a tipologia padrão é a presença maior de municípios de elevada disponibilidade de crédito, tanto agrícola quanto pecuária; b) a região é mais homogênea, sendo que tanto Goiás quanto o Mato Grosso do Sul apresentam padrões acima da média nacional; c) os coeficientes de especialização e entropia são mais próximos de zero, o que define, por um lado, maior grau de diversificação do crédito e, por outro lado, maior equilíbrio na demanda por diferentes tipos de 
crédito, próprio de uma estrutura de produção agrícola mais avançada sob o ponto de vista das relações de produção capitalistas.

\section{Referências}

ARAÚJO, P. F. C. Política de crédito rural: reflexões sobre a experiência brasileira. Brasília, DF: CEPAL. Escritório no Brasil/IPEA, 2011. (Textos para Discussão CEPALIPEA, 37). 65p.

ALVES. E. ROCHA. D.P. Ganhar tempo é possível? In: GASQUES. J.G; VIEIRA FILHO. J.E.; NAVARRO. Z. (orgs.). A agricultura brasileira: desempenho, desafios e perspectivas. Brasília: IPEA, 2010. Cap. 11, p.275-290.

BANCO CENTRAL DO BRASIL. Anuário Estatístico do Crédito Rural 2000. Brasília-DF: BACEN, 2000. Disponível em: http://www.bcb.gov.br/?RELRURAL 2000. Acesso em: 21 fev. 2013.

Anuário Estatístico do Crédito Rural 2010. Vol. I e II. Brasília-DF: BACEN, 2010. Disponível em: http://www.bcb.gov.br/?RELRURAL2010. Acesso em: 21 fev. 2013.

BARRY, P., \& ROBISON, L. (2001). Agricultural Finance: Credit, Credit Constraints, and Consequences. In R. EVENSON, \& P. PINGALI, Handbook of Agricultural Economics (Vol. 1A, pp. 513-571). Amsterdam: North-Holland. DOI: https://doi.org/10.1016/S1574-0072(01)10013-7

BUAINAIN, A. M.; GARCIA, J. R. Os pequenos produtores rurais mais pobres ainda tem alguma chance como agricultores? In: CAMPOS, S. K.; NAVARRO, Z. A pequena produção rural e as tendências do desenvolvimento agrário brasileiro: ganhar tempo é possível? Brasilia: CGEE, 2013.

BUAINAIN, Antônio Márcio; SANTANA, Carlos A. M.; SILVA, Felipe Prince; GARCIA, Junior Ruiz; LOYOLA, Pedro. O tripé da política agrícola brasileira Crédito rural, seguro e Pronaf. In: BUAINAIN, Antônio Márcio; ALVES, Eliseu; SILVEIRA, José Maria da; NAVARRO, Zander. 0 mundo rural no Brasil do século 21: a formação de um novo padrão agrário e agrícola /, editores técnicos. - Brasília, DF: Embrapa, 2014.

CAVALCANTE, A.; CROCCO, M.; JAYME JR. F.G. Preferência pela liquidez, sistema bancário e disponibilidade de crédito regional. In: CROCCO, M. \& JAYME JR. F. G. (orgs.). Moeda e território: uma interpretação da dinâmica regional brasileira. Belo Horizonte: Autêntica, 2006. 
CHICK, V. Bancos regionais: algumas lições da experiência europeia. In: CROCCO, M. \& JAYME JR. F. G. (orgs.). Moeda e território: uma interpretação da dinâmica regional brasileira. Belo Horizonte: Autêntica, 2006.

CLOKE, P., MARSDEN, T., \& MOONEY, P. (2006). Handbook of Rural Studies. Thousand Oaks, California: SAGE Publications Ltd.

CONNING, J., \& UDRY, C. (2007). Rural Financial Markets in Developing Countries. In R. EVENSON, \& P. PINGALI, Handbook of Agricultural Economics (Vol. 3, pp. 22513031). Amsterdan: North-Holland.

CROCCO, M. \& JAYME JR. F. G. O ressurgimento da geografia da moeda e do sistema financeiro. In: CROCCO, M. \& JAYME JR. F. G. (orgs.). Moeda e território: uma interpretação da dinâmica regional brasileira. Belo Horizonte: Autêntica, 2006.

CROCCO, M. A. et al. Metodologia de identificação de arranjos produtivos locais potenciais. Texto para Discussão, CEDEPLAR: Universidade Federal de Minas Gerais, n. 212, p.1-28, jul. 2003. Disponível em:<http://www.cedeplar. ufmg.br/pesquisas/td/TD202012.pdf> Acesso em: 29 jun. 2012.

CROCCO, M. A. Metodologia de identificação de aglomerações produtivas locais. Nova Economia, Belo Horizonte, v. 16, n. 2, p. 211-241, maio/ago, 2006. DOI: https://doi.org/10.1590/S0103-63512006000200001

DELGADO, A. P.; GODINHO, I. M. Medidas de Localização da Actividades e de Especialização Regional. In: COSTA, J. S.; DENTINHO, T. P.; NIJKAMP, P. (Coord.). Compêndio de Economia Regional: métodos e técnicas de análise regional. Vol. II. $1^{\mathrm{a}}$ ed. Cascais: Principia, 2011. (pp. 15-35).

HADDAD, Paulo Roberto (Org.). Medidas de localização e de especialização. In: Economia regional: teorias e métodos de análise. Fortaleza: Banco do Nordeste do Brasil, 1989.

HOFFMANN, Rodolfo. Distribuição de Renda: Medidas de desigualdade e Pobreza. EDUSP: São Paulo, 1998.

CHANG, Ha-Joon. Chutando a escada: a estratégia do desenvolvimento em perspectiva histórica. São Paulo: Editora UNESP, 2004.

FROTA, A. B. \& CAMPELO, G. J. de A. Evolução e perspectivas da produção de soja na região Meio-Norte do Brasil. Disponível em http://goo.gl/XNDIKW (acesso 29/10/2013). 
FURTADO, C. Teoria e política do desenvolvimento econômico. São Paulo: Paz e Terra, 2000.

FÜRSTENAU, Vivian. A política de crédito rural na economia brasileira pós 1960. Ensaios FEE, Porto Alegre, 8 (1):139-154, 1987.

GASQUES, J. G.; VERDE, C. M. V. \& OLIVEIRA, J. A. F. G. De. Crédito Rural e Estruturas de Financiamento. Texto para Discussão 1036. Brasília: Ipea, 2004.

GOMES, S. T. Diagnóstico da pecuária leiteira do Estado de Minas Gerais em 2005: relatório de pesquisa. - Belo Horizonte: FAEMG, 2006. 156 p.

GONZÁLES-VEGA, C. G. Comportamiento de los acreedores agropecuarios al racionar el credito: la Lei de Hierro de las Restricciones a las Tasas de Interes. In: ADAMS, Dale W. et al. (Ed.). Crédito agricola y desarrollo rural: la nueva visión. Columbus, Ohio, The Ohio State University, 1987.

HARVEY, D. Os Limites do Capital. São Paulo: Boitempo, 2013.

IBGE - Instituto Brasileiro de Geografia e Estatística. Pesquisa Pecuária Municipal 2000, 2010. Disponível em: http://goo.gl/etPEZS (último acesso em 11/02/2014).

IPEA - Instituto de Pesquisa Econômica Aplicada. Estrutura produtiva avançada e regionalmente integrada: desafios do desenvolvimento produtivo brasileiro (Capítulo 10: Política de crédito rural). Brasília: Ipea, 2010.

IPEA - Instituto de Pesquisa Econômica Aplicada. Caracterização e Análise da Dinâmica da Produção Agropecuária na Amazônia Brasileira: Uma análise a partir do Censo Agropecuário 2006(Relatório de Pesquisa). Brasília: Ipea, 2013.

LÉNA, Philippe. Diversidade da fronteira agrícola na Amazônia. In: AUBERTIN, Catherine (Org.). Fronteiras. Brasília: Editora da UNB; Paris: ORSTOM, 1988.

MARGULIS, Sérgio. Causas do Desmatamento da Amazônia Brasileira. 1a ed. Brasília: Banco Mundial, 2003.

MEIER, Gerald M. Leading Issues in Economic Development 8th Edn. Published by Oxford University Press, 2001.

MEZZADRI, F. P. Cenário Atual da Pecuária de Corte - Aspectos do Brasil com Foco no Estado do Paraná. Curitiba: SEAB/DERAL/DCA, 2007. 
MONASTERIO, Leonardo. Indicadores de análise regional e espacial. In: CRUZ, Bruno de Oliveira. (Org.). Economia regional e urbana: teorias e métodos com ênfase no Brasil. Brasília: Ipea, 2011.

OLIVEIRA, F. A Reconquista da Amazônia. In: D'INCAO, M. A. e SILVEIRA, I. M. (Orgs.). Amazônia e Crise da Modernização. Belém: Museu Paraense Emílio Goeldi, 1994. pp. 85-95.

RODRIK, D. Development Strategies for the 21st Century. Annual World Bank Conference on Development Economics 2000. Disponível em: http://csf.rrojasdatabank.info/wbdevecon00-7.pdf.

ROMERO, J. P. \& JAYME JR. F. G. Crédito, preferência pela liquidez e desenvolvimento regional: o papel dos bancos públicos e privados no sistema financeiro brasileiro (2001-06). Ensaios FEE, Porto Alegre, v. 34, n. 1, p. 253-286, jul. 2013.

SANTANA, Antônio Cordeiro de (coord.). O fundo constitucional de financiamento do norte e o desenvolvimento da Amazônia. Belém: M\&S Editora, 2002. 